\title{
Le Journal d'une Femme de Chambre: Mirbeau Renoir Buñuel
}

Francisco Villena ${ }^{1}$

1. Doctor en literatura latinoamericana por Ohio State University. Licenciado en filología hispánica por la universidad de Alicante. Se ha desempeñado en la enseñanza en UPenn, Princeton y, más recientemente, lona College; en la planificación didáctica para el departamento de educación español; y en la edición. Su trabajo ha girado en torno a Fernando Vallejo y Lucía Etxebarria. La universidad Javeriana de Bogotá sacó su libro Las máscaras del muerto, sobre el antioqueño, y Planeta su edición conmemorativa de Amor, curiosidad, prozac y dudas. E-mai: fvillena@gmail.com 


\section{Resumén}

Este estudio analiza la adaptación de la novela de Octave Mirbeau, Le journal d'une femme de chambre, a manos de Jean Renoir y Luis Buñuel. Se pueden apreciar semióticas de raigambre diversa, insertas en los ejes raigales de su propia obra artística. Al margen de los lenguajes diferentes que implican el cine y la literatura, se puede apreciar que el genio creador de los tres autores aporta una impronta particular que evidencia cambios en la narración: el ambiente creado en torno al discurso, el tono utilizado, la definición de los personajes y los tres finales distintos vienen determinados por tres fuerzas artísticas que produjeron tres producciones culturales originales y diferenciadas.

\section{Palabras-clave}

Mirbeau, Renoir, Buñuel, adaptación, narración, discurso, cine, literatura

\section{Abstract}

This study analyzes the adaptation of Octave Mirbeau's novel, Le journal d'une femme de chambre, at the hands of Jean Renoir and Luis Buñuel. Different semiotic roots can be found, embedded in the main axes of each artists' work. Besides the different languages involving film and literature, one can see that the creative genius of the three authors contributes a particular imprint that involves changes in the narration: the atmosphere created around the speech, the tone used, the characters' definition and three different endings are determined by three artistic forces which produced three distinct and original cultural productions.

\section{Keywords}

Mirbeau, Renoir, Buñuel, adaptation, narration, discourse, film, literature 
temáticas

livres

Se ha escrito mucho sobre teoría fílmica y teoría literaria, las implicaciones entre ambas, y cómo todo ello afecta a las adaptaciones. Este bagaje teórico subyace en la base del presente estudio; sin embargo, en el caso de la novela de Octave Mirbeau y las adaptaciones de Jean Renoir y Luis Buñuel podemos hablar simplemente de tres creadores, tres poéticas, y tres circunstancias que, además de implicar semióticas de raigambre diversa, insertan la narración expuesta dentro de los ejes raigales de su propia obra artística.

Al margen de los lenguajes diferentes que implican el cine y la literatura, se puede apreciar que el genio creador de los tres autores aporta una impronta particular que evidenciará cambios en una narración que podría ser muy similar en primera instancia; la atmósfera creada en torno al discurso, el tono utilizado, la definición de los personajes, y los tres finales distintos vienen determinados por tres fuerzas artísticas.

De forma paralela al carácter artístico de los tres autores hay que situar el contexto de producción de las obras, ya que devendrá determinante en el resultado final de las mismas. La literatura y el cine son totalmente disímiles en este aspecto: el cine implica una gran inversión económica que los productores quieren no sólo amortizar sino rentabilizar al máximo; esta circunstancia puede determinar completamente la concepción de la obra cinematográfica - como será el caso de la adaptación de Renoir - o puede obligar a asumir ciertas premisas que tamizan la producción - como el mismo Buñuel ha reconocido sobre su película. El escritor de literatura opera, en este sentido, con mayor libertad. Además, en el caso de Mirbeau y Le journal d'une femme de chambre, esta falta de compromisos más allá de la propia obra resulta evidente, ya que, en un primer momento, Mirbeau no se propuso publicar la novela. Fue una continuación de su estudio sobre la realidad francesa, tras 
Le jardin des suplices; en esta ocasión, indagó en las miserias de la burguesía rural francesa de la Belle Époque.

Las adaptaciones de Renoir y Buñuel entran en la categoría que Jorge Urrutia (1984) califica como "reelaboración o crítica del tex to literario". Ni en el caso de Renoir ni en el de Buñuel se aprecian, simplemente, paralelismos, desviaciones, sometimientos o libertades creativas; ambos toman la obra de Mirbeau como punto de partida para reelaborar el texto, aportando o eliminando elementos, y cada director, desde su perspectiva y sus circunstancias concretas, llega a articular un nuevo discurso que propone una relectura crítica de la obra literaria.

\section{Algunas consideraciones teóricas}

El cine es un medio narrativo y, como la literatura, es un arte basado en el lenguaje. El lenguaje consiste en vocabulario, gramática y sintaxis. El vocabulario consiste en palabras, que representan cosas o abstracciones, mientras que la gramática o la sintaxis son medios por los que las palabras se ordenan. El vocabulario del film es simplemente una imagen fotografiada, real o digitalizada; la gramática y la sintaxis del film residen en los procesos de edición y montaje en los que las tomas se ordenan.

Paralelamente a esta explicación se ha de aportar un razonamiento que parece olvidarse en algunos estudios sobre adaptación cinematográfica. Muchos de los críticos que han escrito sobre adaptaciones cinematográficas - Charles Eidsvik, Phebe Davidson, James Naremore, Fred Marcus, Ado Kyrou, Antoni Verdaguer, Jaume Fuster, Deborah Cartmell, Imelda Whelehan, etc. - insisten en el hecho de que el cine y la literatura implican lenguajes, circunstancias, propiedades, contextos de producción distintos; estudian las interrelaciones que se pueden establecer sobre la base de las posibles influencias en el tipo de narración; sin embargo, no plantean la posibilidad de 
ano I número |

temáticas

livres

sobrepasar los departamentos estancos de la organización académica que ha establecido límites claros entre la literatura y el cine.

Jorge Urrutia propone algo distinto en su aproximación a la materia. Comenta en Imago Litterae cómo los teóricos del précinéma veían que el escritor puede llegar a topar con las limitaciones de la lengua. Por otro lado, tendríamos las consideraciones de Eisenstein, el cual acude a la literatura para resolver problemas fílmicos, incidiendo en la idea de que los cineastas tuvieron en los escritores a precursores ilustres a quienes sólo les faltó una cámara para ser genios del cine. Etienne Fuzellier resume estas ideas de la siguiente manera:

Il s'agit de voir dans la littérature non pas un répertoire d'oeuvres à traduire en images, mais une expérience millénaire qu'a perfectionné sans cesse les moyens d'émouvir et d'interesser les hommes par des artifices, et spécialement de présenter à leur imagination des données fictives qui leur procurent un plaisir et un enrichissement particuliers. (URRUTIA, 1984: 32)

El conocimiento del cine nos ha permitido distinguir ciertas construcciones que, de hecho, ya existían anteriormente. Incluso es posible que el uso de dichas construcciones sea más corriente y más exagerado en la literatura contemporánea, pero la invención es antigua. El cine las tomó de la literatura decimonónica y descubrió, el cine para la literatura y para sí mismo, posibilidades insospechadas (URRUTIA, 1984: 41). De ahí que se puedan llegar a plantearse las implicaciones mutuas del cine y la literatura en la repartición del campo semántico - en la transformación de la forma en contenido -, y si sus diferencias no se basan más en las posibilidades narrativas a las que el espectador está acostumbrado, que a las características “intrínsecas” de ambas formas artísticas.

\section{Tres creadores, tres poéticas, tres circunstancias}


contex to del cine comercial; para Renoir, Holly wood determina la despolitización y el tono cómico-romántico de la obra; para Buñuel, las constricciones del cine comercial francés le obligarán a producir una de sus películas menos cáusticas. El aragonés comenta qué razones justifican esta circunstancia:

\begin{abstract}
Por un lado, el intento de hacer un cine industrial honrado, que interese al público, que no lo haga salir de la sala. Porque yo soy muy consciente de que se ha invertido dinero en la película, está el trabajo de mucha gente, y eso da una cierta responsabilidad. Por otra parte está el imperativo subconsciente, que trata de salir a la luz. Filmo para el público habitual y también para los amigos, para los que van a entender tal o cual referencia, más o menos oscura para los demás. Pero procuro que estos últimos elementos no entorpezcan el discurso de lo que estoy contando. (BUÑUEL apud PÉREZ TURRENT; DE LA COLINA, 1993: 135)
\end{abstract}

Sin embargo, en ambos casos, a pesar de las imposiciones que la industria ejerce sobre las producciones, se pueden apreciar elementos que circunscriben ambas películas en la evolución artística y personal de los directores, formando parte de una misma poética, que obligaría a estudiar qué elementos hay en las películas por las obligaciones del mercado y cuáles pertenecen al discurso personal de los creadores.

Una pregunta que surge de manera casi instantánea es por qué los dos directores determinaron hacer una adaptación de una novela decadentista, profundamente crítica con su contexto social, y con claras implicaciones ideológicas, en un entorno industrial que no parecía el más idóneo para aceptar ese tipo de cuestionamientos. Se da la circunstancia en ambos directores de que tenían en mente filmar este proyecto bastante tiempo atrás. Por lo tanto, se pueden apreciar circunstancias casi antagónicas para el desarrollo de este proyecto: un cine comercial y una obra cuestionadora de los pilares básicos de la sociedad burguesa.

Tras Simón en el desierto, Buñuel preparó, junto a Carrière, los guiones de El monje y Là-bas, basados en la novela gótica de Lewis y en la del 
ano I número I

temáticas

livres

decadentista Huysmans, proyectos que finalmente no verían la luz. Sin embargo, el aspecto crítico de estas novelas aparecería posteriormente en Le journal d'une femme de chambre y Belle de jour. Buñuel vuelve a Francia para hacer un cine comercial donde podrán verse algunos de sus elementos subversivos. Las transgresiones de esta última fase de su producción, cuando ha visto alejarse del horizonte socio-político las posibilidades revolucionarias, se centran en los modelos narrativos, buscando formas alternativas de oposición y resistencia al cine clásico de Hollywood, tan al servicio de los valores establecidos (FUENTES, 2000: 164).

En un contexto similar habría que situar a Jean Renoir, quien se exilia a Estados Unidos desde enero de 1941 hasta noviembre de 1949, realizando seis películas en total, cinco en Hollywood y una en Nueva York. La dinámica del cine comercial determinará profundamente el tipo de películas que realizará en este período. Renoir en sus Écrits lamenta este hecho al hablar de su experiencia americana:

C'est en 1946 que j'ai mis en images un sujet qui me tenait à coeur depuis longtemps: Le Journal d'une femme de chambre, d'Octave Mirbeau. Je comprends maintenant que je n'ai pas tiré de ce sujet en or tout ce que j'aurais dû. En un mot, je n'ai pas osé: il était difficile de faire autrement à une époque où le cinéma américain, replié sur lui-même et dominé par la facilié, préférait à out autre genre l'épopée guerrière, tout le 'western'. J'espérais faire ressortir le côte baroque, atroce, froidement cruel de l'oeuvre: parti avec ces excellentes intentions, je me suis laissé aller à trop considérer l'opinion publique, et c'est toujours dangereux por la création. J'ai trouvé en Paulette Goddard et Burgess Meredith des interprètes qui ne demandaient qu'à 'aller jusqu'au bout', et tiens maintenant à leur render homage. (BELFOND, 1974: 55-56)

Los tres creadores parten de una línea ideológica, que si bien no es idéntica, participa de elementos cuestionadores sobre la realidad política y social. Buñuel, como lo definió su propia esposa, es un antitodo que perteneció al movimiento surrealista no únicamente por sus implicaciones estéticas sino también por las políticas. En contexto de producción de Le journal d'une femme de chambre, Buñuel se ha distanciado ya de un comunismo dogmático 
o un ideario partidista concreto; de todos modos, sigue siendo un eterno inconforme. De especial valor son sus consideraciones en "El cine, un instrumento de poesía", conferencia que fue publicada en 1958 por la revista Universidad de México. En la parte final señala:

\begin{abstract}
Hago mías las palabras de Emers, que define así la función de un novelista (léase para el caso la de un creador cinematográfico): "El novelista habrá cumplido honradamente cuando, a través de una pintura de las relaciones sociales auténticas, destruya las funciones convencionales sobre la naturaleza de dichas relaciones, quebrante el optimismo del mundo burgués y obligue a dudar al lector de la perennidad del orden existente, incluso aunque no nos señale directamente una conclusión, incluso aunque no tome partido ostensiblemente". (BUÑUEL apud LÓPEZ VILLEGAS, 2000: 69)
\end{abstract}

Mirbeau fue uno de los ideólogos más iconoclastas de las letras francesas de finales del siglo XIX y principios del XX. Mirbeau expone en sus textos los presupuestos básicos de un anarquismo muy sui generis, donde entran en conflicto nihilismo, humanismo y mesianismo. Escribe contra la familia, la escuela, la iglesia, el ejército, la justicia, el estado, la democracia, la burguesía, el capitalismo. En sus obras prácticamente todo se retrata desde una perspectiva negativa e incluso en sus apariciones en prensa se encuentra el mismo tono: "J' ai beaucoup étudié la vie. Elle est infiniment absurde et infiniment douloureuse" (Mirbeau 'Un Joueur', Le Figaro 27/I/1889).

Renoir, por su parte, sin adscribirse a ningún partido político o una clara línea ideológica, introduce críticas sociales en sus películas. Los cuestionamientos sobre la realidad son más frecuentes en sus películas francesas, aunque se pueden apreciar pequeños guiños en algunas de sus películas americanas, como The Southerner (1945) y Salute to France (1944). Respecto al contenido político de Renoir, Daniel Serceau comenta:

La politique de Renoir ce n'est pas cela; c'est une analyse qui ne se soumet pas au savoir institué, qui' il soit marxiste, ou communiste, ou autre. Sa lecture politique non censurée porte sur une transcription du fonctionnement social actuel; le fait divers sert de révélateur à l'analyse, transgressant les catégories du vasoir, comme ultérieurement le firent ces autres virtuels gauchistes. (SERCEAU,1981: 10) 
Además, coincide en el tiempo de filmación de Le journal d'une femme de

ano I número I

temáticas

livres chambre con un período de transición si no ideológico, sí al menos militante. “Après Le Journal d'une Femme de Chambre et le nouvel échec de la gauche dans les années qui suivent la Libération, Renoir rompt définitivement avec les illusions du Front Populaire et le point de vue idéaliste, en tous cas populiste" (SERCEAU, 1981: 237).

\section{Adaptaciones / Creaciones}

La novela de Octave Mirbeau y las películas de Jean Renoir y Luis Buñuel constituyen tres creaciones singulares de un universo que, en primera instancia, desarrolló Mirbeau. Desarrollando la categorización que propone Jorge Urrutia, siguiendo a Pio Baldelli, se puede apreciar que ni Renoir ni Buñuel proponen la variación de algunos episodios o personajes, sino que ambos directores en sus películas pretenden reelaborar el texto literario.

Las adaptaciones de Renoir y Buñuel muestran la interrelación de las teorizaciones, divergentes pero complementarias, del précinéma y de Eisenstein. En sus películas se muestra una estrecha imbricación de los discursos literario y fílmico; desde la conceptualización misma de sus películas en las que el diario es una pieza clave en torno al cual gira, por medio de Célestine, el contenido ontológico propio de la película. De ahí el mismo título y la constante referencialidad a la escritura.

Además, la narración misma en las dos películas se vertebra en torno a géneros discursivos que, tradicionalmente, se asocian a la literatura, como la novela romántica o gótica; de este modo, consiguen una mayor imbricación respecto al texto de Mirbeau, aportando rasgos considerados literarios a un lenguaje de imagen y sonido, y se proyectan hacia un discurso totalizador, en sentido semiótico (forma/contenido), de mayor complejidad y sentido artístico. 
El punto axial de las tres obras y su objetivo extranarrativo difiere sustancialmente. La violación de Claire es el momento principal de la novela de Mirbeau y un punto importantísimo en la narración que propone Buñuel. A partir de esta acción, Mirbeau, con una ambientación decadentista carente de valores en cualquier estrato social, tratará de mostrar la espiral amoral de la sociedad que retrata en la que entra Célestine, la cual acaba obsesivamente enamorada de Joseph, y al final de la novela escribe:

\footnotetext{
Je me ferai faire un joli costume d'Alsacienne... avec du velours et de la soie... Au fond, je suis sans force contre la volonté de Joseph. Malgré ce petit accès de révolte, Joseph me tient, me possèds comme un démon. Et je suis heureuse d'être à lui... Je sens que je ferai tout ce qui' il voudra que je fasse, et que j'irai toujours où il me dira d'aller... jusqu' au crime... (MIRBEAU, 1900: 519)
}

Para Buñuel, la acción de la violación de Claire posee una fuerza narrativa inmensa que, además, se convierte en una imagen plenamente "buñueliana", con un traveling y un primer plano de sus piernas ensangrentadas con un caracol deslizándose. Célestine, entonces, se aproximará a Joseph con el único objetivo de cerciorarse de que fue él quien violó y asesinó a la niña. Para ello utiliza los recursos que tiene a su disposición: conquista la atención y los deseos de Joseph y, tras obtener su confesión, no duda en denunciarlo inventando pruebas. Finalmente, Célestine, según el guión de Carrière y Buñuel, acaba con Mauger para mostrar su interés de ascensión social y desarraigo afectivo.

Renoir en su película ni siquiera menciona este episodio. El aspecto principal de su película radica en la comicidad con la que se narran las conquistas de Célestine; paralelamente, se muestra cómo éstas la pueden ayudar para conseguir solvencia económica. Bajo este nuevo prisma, Renoir introduce la lucha de cuatro personajes por conquistar las atenciones de Célestine: Joseph, Mauger, Monsieur Monteil, y su hijo Georges. Los episodios giran en torno a los intereses de estos personajes por Célestine. La carga política o de crítica social que aparece en la novela de Mirbeau o la película de Buñuel desaparece 
ano I número |

temáticas

livres

en la adaptación de Renoir, más interesado en narrar una historia que pudiera satisfacer las expectativas del espectador típico de Hollywood.

Mediante un tono en el gozne entre la comedia y el romanticismo, Renoir muestra la conquista final de Georges Monteil, personaje de poca relevancia en la novela y que no aparece en la película de Buñuel, tras una lucha de corte heroico con Joseph. Es el típico "happy ending” que busca satisfacer al público. La oposición binaria de las películas románticas aparece claramente en su propuesta. Georges, el personaje bueno, sentimental, heroico por su nobleza, vence a Joseph, el personaje malo que no duda en matar a Mauger, ya que era su adversario en la conquista de Célestine.

La espacialidad físico-temporal difiere aportando nuevos datos para el análisis. Mirbeau sitúa la acción en la Belle Époque para criticar ciertos estratos sociales y muestra el desencanto de una época aparentemente hermosa, pero inserta en escándalos como el affaire Dreyfus. Además, muestra el paso de Célestine por distintas casas de la Francia rural donde se encuentran los mismos vicios y valores. Buñuel y Renoir prefieren centrar el desarrollo de la trama en una sola casa. Buñuel sitúa la película en los años de su juventud, 1920-1930, momento de la efervescencia de los fascismos en Europa. Una época que conocía mejor que la Belle Époque y que, probablemente, le daba más juego para desarrollar un discurso crítico, al tener más conocimiento de ese período, aunque Buñuel señale que la única razón por la que cambió de momento histórico fue para no tener el engorro de reconstruir ese ambiente. Renoir, con la dinámica establecida por los estudios de Hollywood, nos muestra una Francia rural atemporal, que podría situarse con la misma facilidad a finales del siglo XIX que a principios o, incluso, mediados del siglo XX. Para Mirbeau y Buñuel el contexto físico y temporal será importante para desarrollar sus discursos críticos, pero, en el caso de Renoir, esta circunstancia será marginada en beneficio de desarrollar un argumento donde el contex to histórico o espacial es anecdótico y, en algunos instantes, meramente pintoresco. 
Los personajes en las distintas creaciones en torno a Le journal d'une femme de chambre han sido diseñados de formas distintas para satisfacer su función en la trama general de las obras a las que pertenecen. El personaje central en todas ellas es Célestine, aunque no siempre se presenta como epicentro de la acción que se desarrolla. Por ejemplo, en la adaptación de Buñuel, Célestine no cobra autonomía e importancia en el relato hasta el asesinato de Claire. A partir de ese momento se muestra como una mujer dura y muy lista para conseguir sus objetivos, que pasan por delatar a Joseph y ascender socialmente, al final a través de Mauger. Célestine, según Buñuel, entra en la dinámica que anteriormente había criticado al comportarse igual de despótica e intolerante que Madame Monteil.

Renoir nos la muestra como un personaje cómico en la búsqueda de conseguir una casa para ella, según comenta al principio de la película, y la estratagema pasará por acentuar una sentencia que realiza en los primeros momentos de la narración: "no more love for Célestine”.

Mirbeau profundiza mucho más que los dos anteriores autores en la psicología de Célestine. Muestra cómo se ensucia moralmente y entra en la dinámica de la sociedad que critica, acabando maniatada metafóricamente a los deseos de Joseph. Además, Mirbeau ofrece un retrato de Célestine donde la religión tiene una gran importancia. Acude periódicamente a la iglesia para entrar en la vida social de la Francia rural. Es una herramienta narrativa para criticar a la Iglesia. Célestine comenta su iniciación sexual mediante una "violación consentida" que tuvo lugar en su más tierna adolescencia. Todo el constructo psicológico en torno a Célestine ayudaría al lector a entender mejor su forma de actuar y cómo es posible el desenlace, donde, desatada de cualquier razonamiento, no duda en marchar con un criminal a seguir viviendo su vida.

El retrato más aguzado que se ofrece de Joseph es el de Buñuel; además la interpretación de Georges Géret ayuda a acentuar la importancia de este 
ano I número |

temáticas

livres

personaje. El Joseph de Buñuel es un sirviente semi-ideólogo ultraderechista que mata a una niña sin el menor arrepentimiento. El argumento, sobre todo a partir de la violación y asesinato de Claire, se teje en torno a la relación entre Joseph y Célestine; de ahí la importancia de desar rollar este personaje. Mirbeau muestra un Joseph con grandes silencios y, prácticamente, quien presenta este personaje al lector es Célestine mediante su diario. De ahí que el final de la novela devenga casi una sorpresa para el lector a pesar de saber la obsesión de Célestine. Para Renoir, Joseph es simplemente un tipo más que un personaje. Es el "malo" que se enfrenta a Georges Monteil por los favores de Célestine.

Monsieur Monteil y Mauger aparecen como personajes secundarios en la trama de las tres propuestas narrativas. Ambos son personajes que se les podría ver cómicos para descargar parte de la densidad de la narración de Mirbeau y Buñuel; mientras que para Renoir son personajes accesorios, participantes en algunos de los gags más graciosos de la película, pero que no ayudan al desarrollo de la trama. En la obra de Buñuel sólo adquiere verdadera importancia al final de la película ya que será con quien Célestine finalmente se case, convirtiéndolo en su sirviente, anulado como personaje en la trama y en la ficticia vida de Célestine.

Monsieur Rabour es uno de los personajes que se tratan de forma más diferente basándose en los intereses de casa autor. Resulta un personaje entrañable en la película de Buñuel, debido a que es el único personaje que muestra grandes atenciones a Célestine tras su llegada a la casa donde va a servir. Su fetichismo resulta cómico. Su muerte, además, coincide con un momento importante en la película: Célestine se marcha a la estación para partir y es el mismo día en que Joseph mata a Claire. Mirbeau retrata el fetichismo como perversión; no le da tanta importancia a este episodio - que sucede en una casa distinta -, y no le dedica más de cinco páginas en toda la novela. Renoir, interesado en satisfacer a la audiencia hollywoodiense, ni siquiera trata este episodio. 
Claire es un personaje secundario en las obras de Buñuel y Mirbeau, pero de vital importancia en el desarrollo de la trama de sus propuestas, como ya se comentó anteriormente. Renoir no introduce este personaje, que podría desviar la atención del propósito principal de la película: la comicidad de las conquistas de Célestine.

La servidumbre se retrata de forma distinta en las tres propuestas. Buñuel y Mirbeau profundizan en mostrar cómo funcionan las relaciones de éstos con los señores a fin de establecer una crítica social; aunque tampoco idealizan a los personajes de la servidumbre. La caracterización de Renoir de estos personajes mueve únicamente a la risa; de ahí la importancia que le da a Louise, que llega a la estación junto a Célestine, siendo un personaje muy cómico a lo largo de toda la película.

La configuración de los personajes está delimitada por la relevancia y la función que éstos deben desempeñar en la trama de las creaciones artísticas. Su aparición y eliminación están supeditados al fin que se ha determinado para ellos, sean críticas sociales, comicidad, romanticismo, etc.

\section{Inserción de Le journal d'une femme de chambre}

\section{en sus obras creativas}

En el caso de Octave Mirbeau, Le journal d'une femme de chambre llega a su producción tras Le jardin des suplices, quizás su obra más reconocida por razones literarias. Profundiza en sus críticas sociales y no pretende entretener al lector, sino más bien despertar una conciencia crítica.

Renoir, a pesar de todas las concesiones que tuvo que realizar por el contexto de producción del que parte, consigue añadir algunos elementos al argumento y forma de disposición que inserta esta película en su obra creativa. Hacia el final del film Célestine se encuentra con Georges 
ano I número |

temáticas

livres

celebrando el 14 de julio, tras una toma excesivamente larga para el ritmo de Hollywood donde se lee "Vive la Republique". Georges se enfrenta a sus padres y el destino burgués que le tenían planeado. Mientras en otra toma se ve a Madame Monteil cerrando las ventanas ante la algarabía formada por la celebración. Así pues, de forma más o menos sutil, Renoir muestra un claro posicionamiento ideológico en un período de posguerra. Esta opinión sobre la inserción de esta película en su producción a pesar del contexto del que parte la comparten algunos críticos como Daniel Serceau:

Quant à Hollywood, si souvent accuse de l'avoir corrompu, nous avons rappelé dans ce livre combien la séquence finale du Journal d'une Femme de Chambre s'inscrit dans la stricte continuité filmique du Crime de Monsieur Lange et des Bas-fonds, portant le processus de collectivisation du meurtre, expression de la révolte de classe spontanée, à son point le plus radical. (SERCEAU, 1981: 235)

Buñuel también sitúa esta película dentro de su trayectoria fílmica. Es una obra que muestra una apropiación bajo su sello. Bajo la apariencia de historia lineal, coherente, y lógica que demandaba el cine comercial se pueden encontrar una serie de críticas que van de lo social a lo político. Se critican los ejes del capitalismo, la burguesía y la nación. Hay críticas al trabajo y al capital, la familia y la iglesia, el país y el ejército. El trabajo es alienante - para quien trabaja - y es una muestra clara de un orden social muy rígido. La familia burguesa se ataca principalmente por su decadencia moral. Lo que le importa a la señora Monteil no es que su marido se acueste con las criadas, sino que este hecho le provoca pérdidas económicas. La iglesia resulta malparada también. Tenemos un sacristán que es ideólogo de un grupo ultraderechista y que firma panfletos reaccionarios y demagógicos. Al igual como, en otra escena, en la que el cura confesor aparece con sus faldas dando patadas a la puerta del señor Rabour con una violencia poco propia, supuestamente, de un clérigo. El binomio paísejército se critica a través de la figura de Mauger, el comandante retirado vecino de los Monteil. Un personaje provocador y carente de cualquier tipo de ética, 
que disfruta arrojando piedras y trastos a la finca de su vecino, sin importar el daño que pueda causar. Joseph, igualmente, es una figura crítica en este sentido, ya que, cometiendo crímenes horrendos, es capaz de postularse como patriota y defender activamente su concepto de nación: antisemita, antiextranjera y ultraderechista - conceptos que Buñuel trata de criticar.

Mirbeau, Renoir, Buñuel matizan la trama según su propia poética creadora y su contexto concreto, realizando, en el caso de Renoir y Buñuel, no sólo una adaptación sino una reescritura de la misma historia. Las propuestas narrativas son distintas, pero no por ello ni mejores ni peores. Tampoco la cuestión de la fidelidad a la novela tamiza la calidad de las adaptaciones. El lector o espectador se haya ante tres creaciones de calidad, aunque de naturaleza diversa. Mirbeau, Renoir, y Buñuel muestran tres prismas por los que mirar a lo que podría considerarse a priori, básicamente, la misma historia. Los tres creadores logran aportar una impronta particular que evidencia cambios en la narración, la atmósfera creada en torno al discurso, el tono utilizado, la definición de los personajes, y los tres finales distintos tan determinados por las fuerzas artísticas que hay detrás de cada una de las creaciones. 


\section{Referências bibliográficas}

ano I número |

temáticas

livres
BELFOND, Pierre. Jean Renoir: écrits 1926-1971. París: Les Bâtiseurs du XX Siècle, 1974.

FUENTES, Víctor. Los mundos de Buñuel. Madrid: Akal, 2000.

LÓPEZ VILLEGAS, Manuel. Escritos de Luis Buñuel. Madrid: Páginas de Espuma, 2000.

MIRBEAU, Octave. Le journal d'une femme de chambre. París: Bibliothèque Charpentier, 1900.

PÉREZ TURRENT, Tomás; DE LA COLINA, José. Buñuel por Buñuel. Madrid: Plot Ediciones, 1993.

SERCEAU, Daniel. Jean Renoir, l'Insurgé. París: Le Sycomore, 1981.

URRUTIA, Jorge. Imago Litterae: Cine Literatura. Sevilla: Alfar, 1984.

\section{Bibliografía consultada}

BLUESTONE, George. Novels into Films. Baltimore: Johns Hopkins Press, 1957.

BUÑUEL, Luis. Le journal d'une femme de chambre. Francia, Italia: Spéva Filmns, Ciné Alliances Filmsonor, Film Produzione, 1963.

CARTMELL, Deborah; WHELEHAN, Imelda. Adaptations: from text to screen, screen to text. Londres: Routledge, 1999.

DAVIDSON, Phebe. Films and Literature: Points of Intersection. Lewinston: Edwin Mellen Press, 1997.

EVANS, Peter. The Films of Luis Buñuel. Oxford: Clarendon Press, 1995.

KYROU, Ado. Luis Buñuel: An Introduction. Nueva York: Simon and Schuster, 1963.

MARCUS, Fred. Film and Literature: Contrasts in Media. Londres: Chandler, 1971. 
MICHEL, Pierre. Les Combats d'Octave Mirbeau. París: Annales Littéraire de l'Université de Besançon, 1995.

NAREMORE, James. Film Adaptation. New Brunswick: Rutgers, 2000.

RENOIR, Jean. The Diary of a Chambermaid. EE.UU.: Camden, 1946. . Lettres d'Amérique. París: Presses de la Renaissance, 1984. 